Int. J. Electrochem. Sci., 15 (2020) $3434-3444$

International Journal of

ELECTROCHEMICAL

SCIENCE

WWW.electrochemsci.org

\title{
Electrochemical Sensor Based on Silver Nanoparticles/Multi- walled Carbon Nanotubes Modified Glassy Carbon Electrode to Detect Cyanide in Food Products
}

\author{
Hongyuan Zhang ${ }^{1, *}$, Dawei Sun ${ }^{2}$, Tieping Cao ${ }^{1}$ \\ ${ }^{1}$ Department of Chemistry, Baicheng Normal University, Baicheng 137000, China \\ ${ }^{2}$ Department of Chemistry, Jilin Normal University, Changchun 130000, China \\ *E-mail: october_hy_zhang@163.com
}

doi: $10.20964 / 2020.04 .32$

Received: 5 December 2019 / Accepted: 31 January 2020 / Published: 10 March 2020

In this study, silver nanoparticles/carbon nanotubes (Ag NPs/CNTs) was successfully synthesized on the surface of glassy carbon (GC) electrode using a facile chemical technique to evaluate determination of cyanide as a toxic substance in food products. The structural properties of synthesized CNTs and Ag NPs/CNTs were studied by scanning electron microscope, energy dispersive X-Ray and X-Ray diffraction analyses. The voltammetric and amperometric techniques were used for electrochemical studies of modified electrodes. The structural studies showed high density, porosity and aspect ratio of the Ag NPs/CNTs electrodes. The cycle voltammetric studies of Ag NPs/CNTs/GC electrode showed sharp and stable oxidation peak at $0.75 \mathrm{~V}$ in $\mathrm{pH} 7$ for cyanide. Amperometry results exhibited that $\mathrm{Ag}$ NPs/CNTs/GC electrode was sensitive, selective and stable to determinate cyanide. The linear range, sensitivity, and detection limit of modified sensor were 0.1 to $210 \mu \mathrm{M}, 0.7192 \mu \mathrm{A} / \mu \mathrm{M}$ and $4 \mathrm{nM}$, respectively which were better values than those obtained in previous researches. Study on the interfere effect of $\mathrm{Br}^{-}, \mathrm{SO}_{3}{ }^{2-}, \mathrm{CH}_{3} \mathrm{COO}^{-}, \mathrm{I}^{-}, \mathrm{C}_{2} \mathrm{O}_{4}{ }^{2-}, \mathrm{Cl}^{-}, \mathrm{SO}_{4}{ }^{2-}, \mathrm{CO}_{3}{ }^{2-}, \mathrm{Ni}^{+2}, \mathrm{Co}^{2+}, \mathrm{HPO}_{4}{ }^{-2}, \mathrm{~F}^{-}$and $\mathrm{Zn}^{+2}$ analytes showed that there was not any interfere in determination of cyanide on Ag NPs/CNTs/GC electrode surface. The recorded amperometrogram results of real sample showed the modified electrode was successfully applied for cyanide detection in apricot juice.

Keywords: Carbon nanotubes; Ag nanoparticles; Cyanide; Electrochemical sensor; Apricot juice

\section{$\underline{\text { FULL TEXT }}$}

(C) 2020 The Authors. Published by ESG (www.electrochemsci.org). This article is an open access article distributed under the terms and conditions of the Creative Commons Attribution license (http://creativecommons.org/licenses/by/4.0/). 